\title{
Compromiso intelectual, de Sartre a Chomsky,y su influencia en América Latina
}

\section{Intellectual commitment, from Sartre to Chomsky, and their influence in Latin America}

\author{
Osbaldo Amauri Gallegos de Dios
}

\section{Resumen}

En este artículo, por medio de un acercamiento de la historia intelectual, se analiza el surgimiento de la figura intelectual en Francia con el "Affaire" o caso Dreyfus para entender las posturas de Jean-Paul Sartre, quien sobresale en la historia de los intelectuales del siglo xx y fue clave en Francia desde la posguerra hasta finales de los años sesenta. Luego se analizan los matices del compromiso de Noam Chomsky como investigador, quien se convirtió en un crítico de la política de Estados Unidos. Finalmente, se analiza el contexto histórico en América Latina en la segunda mitad del siglo $x x$, lo que permitirá comprender por qué las ideas políticas de Sartre y Chomsky han tenido tanta influencia en América Latina.

Palabras clave: Sartre, Chomsky, historia intelectual, compromiso,América Latina.

\begin{abstract}
In “Intellectual's commitment, from Sartre to Chomsky, and their influence on Latin America", through an intellectual history's approach we analyze the birth of the intellectual figure in France that started with Dreyfus Affair, to understand Jean-Paul Sartre's ideas, who was a key figure in France from the 50's to end of the 60's. Then, we analyze Noam Chomsky's commitment nuances as a researcher, who has criticized USA politics. Finally, we analyze Latin America's historic context in the second half of $20^{\text {th }}$ century, which allow us to understand why Sartre and Chomsky's political ideas have had a big influence on Latin America.
\end{abstract}

Keywords: Sartre, Chomsky, intellectual history, commitment, Latin America.

\footnotetext{
-Doctor en Estudios Ibéricos y Latinoamericanos (Universidad de Toulouse, Jean Jaurès, Francia); Posdoctorado ciesas Occidente (julio 2020 - junio 2021). Candidato a investigador nacional sni (2020-2022). osbaldoamauri27@gmail.com ORCID:0000-0002-8469-2037

Fecha de recepción: 16 de junio de 2020. Fecha de aceptación: 30 de noviembre de 2020.
} 
En este artículo titulado "Compromiso intelectual, de Sartre a Chomsky, y su influencia en América Latina" por medio de una revisión de la historia intelectual se analiza el surgimiento de la figura intelectual en Francia para entender las posturas de Jean-Paul Sartre y cómo evolucionó su compromiso. Posteriormente se analiza la figura de Noam Chomsky y los matices de su compromiso como investigador, lo que permite establecer vínculos con Sartre. Finalmente, se analiza el contexto histórico en América Latina en la segunda mitad del siglo xx (la Guerra Fría, la Revolución cubana y el periodo de dictaduras), lo que ayuda a entender tanto la participación de los intelectuales latinoamericanos en búsqueda de justicia, como la influencia de las ideas intelectuales de Sartre y Chomsky.

\section{Historia intelectual e historia de los intelectuales}

La historia intelectual y la historia de los intelectuales, se trata de un acercamiento que ha ganado importancia desde finales del siglo xx en Francia y Latinoamérica. François Dosse en La marche des idées. Histoire des intellectuels, histoire intellectuelle afirma que en la historia intelectual se observa una oscilación entre percibir a los intelectuales como un grupo social particular y la ubicación por su compromiso en las luchas ideológicas y políticas. Desde los años ochenta los historiadores franceses han explorado la historia de los intelectuales, orientándose a partir del modelo del caso Dreyfus, de donde se establece el tipo ideal de intelectual comprometido y de antiintelectualismo (Dosse, 2003: 15-43). Además, Dosse en su ensayo "Histoire intellectuelle" explica que la historia de los intelectuales se ha perfilado como campo de investigación autónomo en la sociología e historia, en un cruzamiento de las historias: política, social y cultural. El estudio de la historia intelectual en Francia empezó a adquirir auge a mediados de la década 
de los ochenta dentro de los historiadores (Delacroix, Dosse, Garcia y Offenstadt, 2010: 378).

La historia intelectual utiliza tres herramientas: el estudio de itinerarios, explicación de las generaciones y la observación de estructuras de sociabilidad. Se busca trabajar de forma conjunta los autores, sus obras y el contexto social, en una aproximación externa que privilegia las redes de sociabilidad, intentando dar cuenta de las obras, trayectorias e itinerarios, más allá de las fronteras disciplinarias, remitiendo a la historia política, las ciencias políticas y la historia de las ideas políticas. La historia intelectual intenta interpretar las obras en el tiempo e inscribirlas en un análisis sincrónico (relación entre el contenido del objeto intelectual y lo que se hace en otros ámbitos de la época) y diacrónico (vincula un texto o un sistema de pensamiento con aquellos que le preceden en el mismo tipo de actividad cultural) (Delacroix et al., 2010: 379-387).

Dentro del contexto de este artículo, sobresale que Dosse sostiene que América Latina ofrece un buen terreno de transferencias culturales del modelo del caso Dreyfus del intelectual comprometido, por su lugar en los procesos de independencia nacional y por sus protestas contra el establecimiento de dictaduras militares (Dosse, 2003: 92).

\section{Surgimiento de la figura del intelectual en Francia}

En Francia durante el caso Dreyfus cristalizó la figura del intelectual y el nacimiento del nuevo grupo portador de valores universales: verdad, justicia y razón (Hourmant y Leclerc, 2012: 10). Así, en ese país los intelectuales participan en la política desde el "Yo acuso" de Émile Zola para defender al capitán Dreyfus (Hofmeister y Mansilla, 2003: 9). Sin embargo, los hombres de letras o pensadores han participado en la búsqueda de justicia y verdad desde el Siglo de Oro y la Ilustración, pero no lo hacían con el 
nombre de intelectuales, sino con el de hombres de letras, filósofos, pensadores u otros. Por lo tanto, en Francia el caso Dreyfus fue el momento histórico icónico de la participación intelectual en la búsqueda de verdad y justicia.

A finales del siglo xx parecía que las discusiones sobre la vida intelectual habían terminado en Francia. Sin embargo, Alain Touraine, un sociólogo francés nacido en 1925, retomó el tema en Comment sortir du libéralisme? (1999) y estableció que cuando no existe un principio efectivo de unidad en la vida social y política es cuando interviene el intelectual, por lo que existen cinco categorías: denunciador, orgánico, utópico, de la acción social y, por último, intérprete, entre quienes se cuenta Touraine (1999: 147-149).

El intelectual denunciador es el que critica al sistema dominante, según Touraine, y representa la figura clásica y más visible del intelectual. Como se verá a continuación en este artículo, Sartre y Chomsky son considerados intelectuales comprometidos y denunciadores, por lo que sus ideas políticas han tenido un gran impacto en América Latina.

\section{Jean-Paul Sartre y el compromiso intelectual}

Jean-Paul Sartre (1905-1980) nació y murió en París, Francia. En 1964 fue galardonado con el Premio Nobel de literatura, pero lo rechazó. Sartre es el puente entre las dos guerras y la posguerra y sus obras posteriores a La Náusea se enfocan en el "compromiso" (Galster, 2001: 14). Los años de la posguerra son los de la "literatura comprometida", con los textos de la presentación de Temps modernes y Qu'est-ce que la littérature? de Sartre (Leymarie, 2003: 155).

Antes de 1939 el escritor francés se encontraba alejado del compromiso, y después de la Segunda Guerra Mundial se convirtió en el intelectual comprometido en todos los frentes de la actualidad política. Sartre relacionaba el compromiso con el hecho de que el escritor debe entender la situación de 
su época porque cada palabra y cada silencio tienen repercusiones, como lo escribió en 1945 en la Présentation des Temps modernes. Por consiguiente, después de la guerra comienza el verdadero compromiso de Sartre. Para Sartre, el escritor debe intentar cambiar al mundo, porque el mundo occidental es un tejido de mentiras y el capitalismo le da prioridad al poder económico aparentando una democracia donde la libertad y la igualdad son los valores supremos. De esta forma, el cambio de la sociedad pasa por un cambio de los vínculos económicos entre los individuos (Monnin, 2008: 24-38). Monnin afirma que Sartre no participó mucho en la "Resistencia", contrario a lo que señalaron los periódicos en Estados Unidos durante su primera visita en 1945 a ese país. Esta situación contribuyó a su reputación en Europa y no fue desmentida por Sartre. Pueden distinguirse cuatro etapas en el compromiso de Sartre:

L'engagement politique de Sartre commence donc après-guerre. On y distinguera quatre périodes: de 1945 à 1952, période la plus tendue de la Guerre Froide où Sartre ne parvient pas à se rallier aux communistes sans toutefois pouvoir les désavouer totalement; de 1952 à 1956, quatre ans de compagnonnage avec le PCF; de 1956 à 1968, où Sartre s'intéresse plus particulièrement aux problèmes des colonisés et aux nouvelles révolutions (Cuba, la Chine); puis de 1968 à sa mort, où Sartre retrouve l'extrême gauche (Monnin, 2008 : 39).'

Winock en Le siècle des intellectuels señala que, hasta la guerra, Sartre fue un poco insensible a las responsabilidades políticas del escritor. Sartre se explicó en 1975 diciendo

I. El compromiso político de Sartre comienza entonces después de la Guerra. Ahí, se distinguirán cuatro periodos: de 1945 a 1952, el periodo más tenso de la Guerra Fría cuando Sartre no alcanzó a reunirse con los comunistas sin poder desaprobarlos totalmente; de 1952 a 1956 cuatro años de compañero de ruta con el PCF (Partido Comunista Francés); de 1956 a 1968 cuando Sartre se interesó más particularmente por los problemas de la colonización y las nuevas revoluciones (Cuba y China); después de 1968 hasta su muerte, cuando Sartre se encontró con la extrema izquierda (la traducción es mía). 
que antes de la guerra se consideraba una simple persona y no veía la relación entre su existencia y la sociedad. Sartre detestaba la moral, la hipocresía y su dominación social, a la que oponía un temperamento anarquista, libertario y pacifista. Es contra la burguesía que, como opinó, escribió La náusea y El muro. Para Sartre, todo cambió en 1939 cuando recibió su hoja de movilización de la guerra y comprendió que era un ser social, lo que fue el tránsito del individualismo al socialismo. Al final de la guerra, Sartre y Camus se convirtieron en los faros de la nueva generación y el existencialismo, y la crítica al "arte por el arte" que fue detallada en Qu'est-ce que la littérature? resultó insoportable para los escritores comprometidos y también para los que no lo estaban. Sin embargo, Sartre afirmó, en Présentation des Temps modernes que el escritor debe aceptar su época y no perderse nada de ella, porque no se puede evadir, incluso si decide callarse; por tal razón, el escritor debe darse cuenta que todo escrito posee un sentido y abrazar su época (Winock, 1999: 493-498). Sartre explicó que cada escritor está en situación dentro de su época:

Et Sarte de créer un concept qui va devenir familier à ses lecteurs: 'L'écrivain est en situation dans son époque:chaque parole a des retentissements. Chaque silence aussi.' L'écrivain est appelé à une mission: donner sens à son temps, contribuer aux changements nécessaires. L'impératif de l'engagement est porté à son comble. II ne s'agit plus d'exiger du romancier ou du philosophe d'écrire, en marge de son œuvre, des articles politiques ou de signer des pétitions. Sartre affirme que toute prose, même la fiction, est 'utilitaire', que toute prose engage. Les mots sont des 'pistoles chargés', il convient donc de bien viser, et non de tirer au hasard comme un enfant (Winock, 1999 :498). ${ }^{2}$

2. Y Sartre de crear un concepto que va a volverse familiar con sus lectores:"El escritor está en situación en su época: cada palabra tiene consecuencias. Cada silencio también". El escritor está llamado a una misión: dar sentido a su tiempo, contribuir a los cambios necesarios. La prioridad del compromiso es llevada a su punto más alto. No se trata más de exigir al novelista o al filósofo que escriban, al 
Por otra parte, la obra Qu'est-ce que la littérature? de Sartre se publicó en 1948 y en ella establece: "Yo diría que un escritor está comprometido cuando se esfuerza por embarcar a la conciencia más lúcida y completa, es decir, cuando, tanto para él como para los demás, hace pasar el compromiso de la espontaneidad inmediata a lo reflexionado" (1957: 93). Respecto a la "literatura comprometida" ("Littérature engagée") asevera que un escritor está comprometido cuando se esfuerza por embarcar a la conciencia más lúcida y completa:

Hace falta que el escritor escriba para un público que tenga la libertad de cambiarlo todo, lo que significa, además de la supresión de clases, la abolición de toda dictadura, la perpetua renovación de los cuadros, el derribo continuo del orden, en cuanto tienda a "congelarse". En pocas palabras, la literatura es, por esencia, la subjetividad de una sociedad en revolución permanente (Sartre, 1957: 15I).

\section{Compañero de ruta y el comunismo-marxismo}

Sartre nunca perteneció al Partido Comunista, pero entre 1952 y 1956 permaneció muy cercano como "compañero de ruta”. Para Sartre, el anticomunismo es una actitud política y moralmente inadmisible, por lo que en 1961 mencionó que: "un anticommuniste est un chien, je ne sors pas de là, je n'en sortirai plus jamais" (Cabestan, 2009: 24). ${ }^{3}$ A pesar de la relación variante con el marxismo, que comenzó sobre todo durante los años de "La Ocupación", en 1960 Sartre todavía lo consideraba como una filosofía infranqueable de su tiempo. Para Sartre, el "compromiso" (engagement) es

margen de su obra, artículos políticos o firmen peticiones. Sartre afirma que toda prosa, incluso la ficción, es "utilitaria", que toda prosa compromete. Las palabras son "pistolas cargadas", por lo que conviene entonces de apuntar bien y no tirar al azar como un niño (la traducción es mía).

3. Un anticomunista es un perro, no abandono esa idea y no la abandonaré jamás (la traducción es mía). 
importante para ser libre y existen tres tipos: el compromiso que es condición de la libertad, el compromiso que es un acto de libertad concreta a partir de su inserción en el mundo, y el compromiso como valor o exigencia ética. Respecto a la literatura comprometida, Sartre señala que se encuentra entre el arte por el arte y el realismo socialista; además, la literatura comprometida debe estar comprometida con el presente y se dirige a las personas que comparten ese tipo de preocupaciones. Sartre afirmó que el compromiso está relacionado sólo con los escritores, y es una responsabilidad que no comparten ni los pintores, músicos o poetas (que están más cercanos de los músicos que de los escritores), es decir, el compromiso sólo concierne a las obras literarias. Para Sartre el "intelectual" es un "técnico con un saber práctico" (Cabestan, 2009: 70-115).

Antes de 1952, Sartre, sin adherirse al Partido Comunista, prefirió inclinarse a la ideología comunista que a la ideología liberal del oeste, lo que le permitió mantener su libertad. Sartre en su primera etapa estaba en búsqueda de una tercera opción entre la izquierda y la derecha. Sin embargo, a pesar de conocer las injusticias soviéticas, prefirió no criticar al comunismo, caso contrario a Merleau-Ponty quien renunció a la revista en 1950 (Monnin, 2008: 40 y 41). De esta forma, Sartre se convirtió en un anti-anticomunista:

Cette attitude, ni communiste, ni anti-communiste, va se radicaliser en 1952. Sartre s'en explique dans l'article Les Communistes et la paix. À ce moment-là, comme il l'écrira en $6 \mathrm{I}$, il était déjà d'avis que 'tout anticommuniste (était) un chien' on ne pouvait tergiverser, il fallait s'engager plus à fond dans le choix d'un camp parce que la situation avait changé. Comme Sartre est anti-capitaliste, anti-impérialiste et anti-bourgeois, il ne peut que se ranger aux côtes des communistes. II déclare alors, dans Les communistes et la paix, “(son)

\section{0}


accord avec les communistes sur des sujets précis et limités à partir de mes principes et non de leurs" (Monnin, 2008: 42). ${ }^{4}$

Sartre no ignoraba la dictadura de la URss y los goulags de Stalin, pero mantenía públicamente la idea de que el capitalismo era peor que el socialismo. Incluso, en 1954, después de su viaje a la uRss declaró que la libertad de palabra es total en ese país comunista. Cuando muchos de los intelectuales de izquierda abandonaron el Partido Comunista francés, Sartre a contracorriente, decidió ser el "compañero de ruta" para intentar salvar al comunismo, porque para él no se podía reducir a la experiencia soviética. Monnin señala que a pesar de la ruptura de Sartre con los comunistas, nunca quiso criticarlos porque, como escribió en 1961, creía que un anticomunista es un perro ("un anti-communiste est un chien"). No obstante, en 1968 se dio su ruptura, dejando de ser el "compañero de ruta" de la uRss debido a la invasión en Praga en 1968 (Monnin, 2008: 29-44).

En París durante los años sesenta y setenta se creía que era mejor estar equivocado con Sartre que tener razón con Aron, porque ningún otro pensador, escritor, filósofo o intelectual francés había tenido la capacidad de crear tal sinergia movilizadora con sus intervenciones radicales en la esfera política. Sartre declaró al final de su vida que no fue marxista, lo que se contraponía a lo que él mismo había afirmado antes, cuando señaló que el existencialismo es una ideología parásita del marxismo, aunque después opinó que tal afirmación se trató de un error (Münster y Wallet,

4. Esta actitud, ni comunista ni anticomunista, se va a radicalizar en I952. Sartre lo explica en el artículo Los comunistas y la paz. En ese momento, como él escribirá en 196I, estaba al tanto de que "todo comunista era un perro". No se podía tergiversar, era necesario comprometerse más a fondo en la elección de un campo porque la situación había cambiado. Como Sartre es anticapitalista, antiimperialista y antiburgués, solamente puede acomodarse al lado de los comunistas. Por lo tanto, declara en Los comunistas y la paz "[su] acuerdo con los comunistas sobre temas precisos y limitados a partir de mis principios y no los suyos (la traducción es mía). 
2006: 12-35). En la última etapa de su vida sus ideas fueron cambiando, lo que lo llevó a afirmar que su pensamiento era superior al de los marxistas: "Ici ma pensée est distincte de celle d'un marxiste. Ce qui à mes yeux fait ma supériorité sur les marxistes, c'est que je pose la question de la classe, la question sociale, à partir de l'Être qui est plus ample que la classe” (Münster y Wallet, 2006: 47). ${ }^{5}$

\section{Los años sesenta en Francia y por el mundo}

En 1960, el compromiso de Sartre lo hizo viajar junto a Simone de Beauvoir a Cuba donde fueron recibidos por Fidel Castro y el Che Guevara, quienes les concedieron largas entrevistas. A partir de ese viaje, Sartre publicó un reportaje en France-Soir llamado "Ouragan sur le sucre" (Huracán sobre el azúcar) donde realizó un elogio sobre la nueva sociedad cubana y transmitía un gran optimismo por su evolución. Su compromiso también lo llevó a reclamar la independencia de Argelia y denunciar las torturas en 1960. Ese mismo año viajó con Simone de Beauvoir a Brasil, donde tuvieron un encuentro con estudiantes y hablaron del problema en Argelia. En 1965 Sartre condenó la guerra de Vietnam y participó en el Tribunal Russell; además, como forma de protesta, debido a esta guerra declinó una invitación de la Universidad Cornell en Estados Unidos (Monnin, 2008: 45-49).

En 1964 Sartre fue reconocido con el Premio Nobel de literatura, pero lo rechazó y pagó para que una carta suya fuera publicada en Le Figaro. Ahí, explicó que siempre ha rechazado las condecoraciones oficiales para no dejarse transformar y mantenerse independiente de las institucio-

5. En este caso, mi pensamiento es distinto de los marxistas. Eso que desde mi punto de vista crea mi superioridad sobre los marxistas porque presento las preguntas sobre las clases, la cuestión social a partir del Ser que es más amplia que la clase (la traducción es mía).

\section{2}


nes. Asimismo, creía que aceptar el premio lo acercaría más a uno de los dos bloques de la Guerra Fría, cuando su ambición era el entendimiento entre ambos (Bejerano, 2014).

Las manifestaciones estudiantiles de mayo y junio de 1968 en Francia marcaron a una generación, probablemente provocaron la partida del general Charles de Gaulle en 1969 y condujeron a la reforma Edgar Faure de la Universidad Francesa. Sartre apoyó estas manifestaciones, aunque el conflicto en Francia no tenía nada de marxista y propuso algunas generalidades, porque señalaba que no le correspondía dar consejos en una sociedad con poco compromiso. Una parte del movimiento del 68, en Francia, estaba relacionado con la renuncia de algunos profesores en la Universidad y la aplicación del poder universitario por parte de los estudiantes. Sartre y Raymond Aron tenían puntos de vista opuestos sobre el movimiento del 68 en Francia, lo que le ocasionó fuertes críticas a Aron. Sartre se oponía a Aron en la defensa de la elección de los profesores por parte de los estudiantes y estaba convencido de la posibilidad de una revolución fuera del partido comunista y a su izquierda. Debido a su apoyo por el movimiento, Sartre fue bien visto y respaldado por los estudiantes (Winock, 1999: 701-763).

A finales de la década de 1960 comenzó a disminuir la popularidad de Sartre debido a la oleada estructuralista con Foucault, Lacan y Lévi-Strauss. No obstante, la crisis de 1968 volvió a poner a Sartre en las discusiones porque apoyó al movimiento estudiantil francés y se alió con la extrema izquierda y los estudiantes de corriente maoísta. El 20 de mayo de 1968 aceptó un diálogo con los estudiantes de la Sorbona en París, y ahí surgió el contacto con Benny Lévy, quien fundó en octubre de 1968 el movimiento "Mao" La izquierda proletaria. Con Lévy se reencontró en 1970 para discutir la situación de la izquierda en esa época (Monnin, 2008: 45-49). 


\section{¿El silencio del intelectual comprometido en Francia?}

En Francia a partir de los años setenta comenzó la ruptura con la figura del intelectual comprometido. El universitario tuvo un declive en la vida intelectual a partir de la Segunda Guerra Mundial y hasta finales de los años sesenta, debido a que dos temas ganaron importancia: el colonialismo y el comunismo. En esa época, el compromiso sartreano en la universidad estaba relacionado con la izquierda comunista y muy pocos estudiantes durante los años cincuenta y sesenta se declaraban abiertamente de derecha. Posteriormente, en los años setenta las formas del compromiso cambiaron, por lo que el declive de la figura del intelectual está asociado con su distanciamiento en las universidades y el repliegue de los universitarios e investigadores (Leymarie, 2003: 259-263).

El silencio de los intelectuales en Francia comenzó a partir de los años ochenta y está asociado al desvanecimiento del compromiso, tema que ha sido desarrollado por algunos investigadores. Yves Charles Zarka en La destitution des intellectuels explica que destitución significa que la función del intelectual perdió credibilidad y se vació de contenido, debido a que las condiciones de la toma de palabra en el espacio público cambiaron completamente (2010: 9-31).

Alain Touraine en Comment sortir du libéralisme? asevera que el silencio relativo de los intelectuales en las últimas décadas se explica por el fin de un periodo histórico y está asociado al remplazo del análisis de los sistemas por la interpretación de los actores (1999: 152-154). Además, cabe recordar el derrumbe del bloque soviético y las revisiones ideológicas que contribuyeron a que se haya llamado exageradamente a esa época "el fin de las ideologías", lo que generó un desinterés en la política y que el compromiso literario haya perdido su razón de ser (Denis, 2000: 296).

\section{4}


Noam Chomsky, investigador activista contra el imperialismo

Ninguna idea fue tan extraña para Noam Chomsky como aquella que señala que el rol de los intelectuales es comprometerse y denunciar el poder. Sin embargo, Chomsky es famoso por ser uno de los críticos de la política extranjera de Estados Unidos. Aunque también es conocido por sus ideas sobre el progreso, las revoluciones, la libertad de expresión, el anarquismo, el mercado, los intelectuales, la filosofía, las ciencias y la religión. Por razones lógicas, no utiliza el término socialismo, a pesar de que retoma el anarquismo y uno de sus principios es el socialismo libertario. Además, Chomsky reprocha la falta de objetividad de los intelectuales de izquierda (Chomsky, 2010: IX-XXII).

Chomsky estaba consciente del precio a pagar por tener un rol de disidente dentro de la escena pública, ya que sabía lo que le había pasado a Rosa Luxembourg (asesinada), Antonio Gramsci (prisionero) o Bertrand Russell (prisionero), como lo explica Robert F. Barsky en Noam Chomsky une voix discordante. Chomsky sabía de la importancia de participar activamente, no era suficiente firmar peticiones, enviar dinero o mostrarse a veces en los encuentros; era necesario participar activamente y conocía las consecuencias. A partir de finales de los años sesenta, Chomsky es presentado como el perfecto activista en Estados Unidos (1998: 155-166).

El entorno científico de Chomsky influenció su pensamiento sobre el rol del intelectual, el funcionamiento de las instituciones en las sociedades y el interés de la ciencia por la sociedad. Sus ideas políticas se alimentaron de las ideas libertarias y los movimientos radicales de finales de los años sesenta, de donde surgió su escepticismo sobre la capacidad de algunos activistas que buscan escribir su acción en la Historia. Chomsky apoya a los militantes y las 
luchas populares con militantes comunistas, pero no apoya a las celebridades de izquierda como Marcuse, uno de los gurús de la "nueva izquierda", o al Che Guevara, porque en 1995 afirmó que su actitud le parecía un romanticismo estúpido (Barsky, 1998: 170 y 171). Por ende, Chomsky entendía la importancia de actuar políticamente, lo que aunado a su entorno científico lo llevaron a convertirse en un investigador activista.

\section{América Latina y su relación con Estados Unidos}

En Idéologie et pouvoir, Noam Chomsky afirma que el objetivo principal de la política exterior de Estados Unidos es garantizar la libertad de robar y de explotar. En América Latina aplican esta política desde 1945, como lo explicó el secretario de Estado, Henry Stimson, conocido por el rol que desempeñó en la invasión estadounidense en Nicaragua que permitió imponer la dictadura de Somoza. El principio básico de su política exterior es mantener un orden internacional para que las empresas estadounidenses puedan prosperar, un mundo de "sociedades abiertas" (2004: 12-15).

Este principio de Estados Unidos es garantizar un medio ambiente global favorable a la industria, comercio, agricultura y al mundo financiero establecido por ellos. Cuando el entorno no le favorece, ese país se convierte en enemigo y debe ser disciplinado; dentro de la terminología política estadounidense, los enemigos son tachados de comunistas. Desde 1950 Estados Unidos ha estado enfocado en la protección de "sus" materias primas, sobre todo en América Latina. Para ellos, "comunistas" son aquellos que defienden y utilizan sus propios recursos naturales (Chomsky, 2004: 18-29).

Cuando los países latinoamericanos no aceptan los consejos de Estados Unidos, corren el riesgo de ser "motivados" como lo hicieron con Guatemala. Este tipo de políticas son 
las que aplicaron Kennedy y Johnson contra Cuba y la República Dominicana. Proclaman el principio de que la soberanía en América Latina está limitada por los criterios ideológicos establecidos por la superpotencia del continente, por lo que los gobiernos que se aparten de estos criterios serán culpables de "agresión" y pueden ser atacados por Estados Unidos. Lo más importante es crear en América Latina un clima económico y político que motive las inversiones privadas de capitales nacionales y extranjeros (Chomsky, 2004: 34-37).

Por otra parte, América Latina. De la colonización a la globalización, de Noam Chomsky, se trata de una conversación con Heinz Dieterich donde aborda temas como la Revolución cubana, el golpe de Estado en Chile en 1973 y el movimiento sandinista en Nicaragua, con la participación de Estados Unidos y sus "golpes preventivos" en América Latina. ${ }^{6}$ Chomsky explica la participación de Estados Unidos en el golpe de Estado en Chile en 1973:

Cuando Salvador Allende ganó las elecciones en 1970, el gobierno Nixon-Kissinger trató de impedir que el presidente elegido democráticamente asumiera y conservara el poder. Pero a Washington no le fue posible orquestar un golpe militar "preventivo", debido a lo que la CIA mencionó en sus documentos secretos como la "inercia constitucional" de las fuerzas armadas chilenas. La Casa Blanca necesitó tres años para destruir la economía del país y organizar una facción pro-golpista que acabara con el régimen popular (Chomsky, 1999: 19).

En ese contexto surgió la guerra de Estados Unidos contra Nicaragua, debido a que la administración Carter apoyó a Somoza hasta el final. En 1979, con la caída de Somoza

6. Chomsky señala que después de su viaje a Nicaragua en 1986 se dio cuenta de que ahí se podía vivir con integridad y esperanza. Así, esta calidad de vida en Nicaragua fue lo que provocó que se convirtiera en una amenaza y enemigo de Estados Unidos. Véase Chomsky, I999: 10. 
empezó la intervención militar de Estados Unidos contra los sandinistas. La administración Carter trató de apoyar a elementos conservadores y pro-estadounidenses y llevarlos al poder, mientras que la administración Reagan sencillamente recurrió a la guerra contra Nicaragua (Chomsky, 1999: 32-35).

Chomsky asevera que en las intervenciones estadounidenses en Filipinas, Haití y la República Dominicana, el empeño político es asegurarse de seguir utilizando el 50\% de los recursos mundiales para su 6\% de la población mundial. Desde finales de los años veinte, Estados Unidos ha mantenido esta política exterior en el continente, cuando el presidente Coolidge envió a los Marines a Nicaragua en un golpe que llevó al poder a Somoza y a asesinar a Sandino. La política exterior de Estados Unidos desde los años cuarenta se puede resumir en "protección de nuestras materias primas", supuestamente de los rusos, pero en realidad la protegen de la población indígena de Latinoamérica (Chomsky, 1999: 40-52). ${ }^{7}$

Dentro de esta lógica tanto Nicaragua como Chile se convirtieron en una "amenaza" para Estados Unidos, porque estaban utilizando sus propios recursos para lograr un desarrollo social, económico, nacional e independiente, fuera del control estadounidense, situación que se podía "contagiar" a otros países en América Latina. Existen varios efectos "positivos" para Estados Unidos cuando aplica un embargo, porque aumenta el sufrimiento en el país y como consecuencia aumenta la disidencia interna. Además, el embargo los empuja hacia los rusos, lo que permite justificar cualquier ataque, con lo que sale favorecido. Al país norteamericano no le gustan los gobiernos "comunistas", y

7. Chomsky afirma que no sólo Reagan sino también Kennedy violaron leyes internacionales al establecer diferentes guerras porque Estados Unidos es miembro de la ONU, y según la carta de la ONU es un crimen de guerra usar la fuerza en asuntos internacionales. Véase Chomsky, 1999: 40-52.

\section{8}


llaman así a todo país que busque el bienestar de su población. Estados Unidos durante su historia ha destruido todos los movimientos populares en el continente y ha frenado cualquier avance hacia la independencia por medio de la instalación de dictaduras brutales que mantienen la región bajo control; está obsesionado en garantizar que los recursos del continente estén a disposición de su economía. Finalmente, Chomsky presenta un resumen de la destrucción de Estados Unidos en América Latina y las invasiones que han realizado en el siglo xx en Cuba, Panamá, México, Haití, República Dominicana, Guatemala y Nicaragua, entre otros países; por lo que afirma que sus posturas no tienen nada que ver con Rusia (Chomsky, 1999: 53-59).

El embargo contra Cuba es una prueba más de que Estados Unidos no permite los movimientos populares en Latinoamérica. Chomsky muestra algunas estadísticas sobre los índices de calidad de vida en Cuba, que es lo que realmente molesta a Estados Unidos. Estas estadísticas se basan en la tasa de mortalidad, la mortalidad infantil, la expectativa de vida y la alfabetización. El primer país de América Latina es Cuba, lo que lo convierte en un enemigo de Estados Unidos, por eso han intentado empujarlos hacia los rusos para justificar el embargo y la represión, de forma que no pueda ser un modelo en el continente. Estos índices de calidad de vida lo convierten en enemigo, por eso no pueden tolerar otra Cuba. Estados Unidos en su compromiso con el "imperio de la fuerza" impone el "imperio de la ley" para pacificar, denunciar enemigos oficiales y abordar problemas (Chomsky, 1999: 60-68).

Por consiguiente, Chomsky explica la política exterior de Estados Unidos que busca garantizar la explotación de materias primas en América Latina, por lo que no permite los movimientos populares y llama "comunistas" a quienes busquen el beneficio de la población, lo que le ha permitido crear "enemigos oficiales". 
¿Contra el imperialismo y la mundialización representada por Estados Unidos?

A partir de 1967 se puede observar el compromiso en Chomsky y ha tomado en cierta forma el lugar de Sartre. Igualmente, retoma el compromiso trazado por Wright Mills y Herbert Marcuse, por lo que la visibilidad internacional queda indisociable de una radicalidad política o de una contestación ideológica, como establece François Hourmant en Les intellectuels et le pouvoir: des 'idiots utiles' aux prophètes d'institution (Hourmant y Leclerc, 2012: 8-26).

Chomsky es el crítico más importante de la política exterior de Estados Unidos, como lo señala Vivek Chibber en Noam Chomsky et la longue histoire de l'impérialisme américain. Es reconocido desde los años sesenta debido a sus críticas de la política de Estados Unidos en Vietnam, y sus primeros artículos: "The new mandarins" y "The backroom boys" revelaron algunas de sus cualidades: dominio enciclopédico de los detalles, moralidad intransigente y una capacidad extraordinaria para tratar los asuntos del momento (Bonfiglioli y Budgen, 2006: 94).

El movimiento altermundista se opone al imperialismo con sus empresas privadas y los Estados que los representan. Chomsky es crítico del imperialismo y anticapitalista, y apoya este tipo de movimientos. Para él, un elemento determinante del siglo xx es que desde que Estados Unidos se estableció como potencia mundial ha perseguido un proyecto "mundializador". Chomsky retoma una de las posturas centrales socialistas al señalar que después de la Segunda Guerra Mundial comenzó la segunda fase de la consolidación del imperialismo de Estados Unidos a nivel mundial, porque asumió la responsabilidad de proteger al capitalismo y la democracia contra la agresión de la URSs, bajo el nombre de Guerra Fría. Por consiguiente, el enemigo principal de Estados Unidos ha sido el nacionalismo económico, sobre 
todo en el tercer mundo, como se puede observar en su política exterior desde McKinley hasta George Bush. Es decir, total apoyo a la apertura de los mercados mundiales y la dominación de las empresas estadounidenses. La mundialización para Chomsky no se trata de la difusión global del mercado libre, porque el capitalismo nunca ha sido un mercado libre, sino de la consolidación de empresas estadounidenses a nivel mundial, porque tienen la capacidad de obligar a los Estados a hacerles concesiones, al imponer principios de libre mercado y marginando a las empresas locales (Bonfiglioli y Budgen, 2006: 95-100). ${ }^{8}$

Con su posición frente a la guerra de Vietnam, Chomsky llamó la atención del público no académico; sobre todo es conocido por su crítica de la política exterior de Estados Unidos, debido a que por más de tres décadas ha criticado a su país natal por las mentiras, inhumanidad y homicidios de las políticas de Estado, lo cual es explicado por Neil Smith en Chomsky. Ideas and ideals. Una de las técnicas de análisis de Chomsky es el estilo clásico académico de la acumulación masiva de documentación, con múltiples referencias y fuentes que son frecuentemente ignoradas por historiadores; este estilo le permite tener una excelente documentación sobre todas las guerras que ha emprendido Estados Unidos en el mundo. Para Chomsky es básica la libertad de expresión, lo que lo lleva a ser cuidadoso y adoptar una posición sutil, ya que no cree en los absolutos morales; donde existe libertad de expresión, la elección de

8. Chomsky asevera que el objetivo de la mundialización neoliberal es político,ya que una de las metas es restaurar el poder político de las clases propietarias, que había desaparecido desde la mitad del siglo xx. No cree que el nacionalismo sea el contrapeso para la mundialización, pero valora algunos aspectos de la integración mundial y considera que la consolidación de la Unión Europea es potencialmente progresista, en la medida en que erosiona el culto del Estado-nación, aunque también critica su forma neoliberal. Véase Bonfiglioli y Budgen, 2006: 99 y 100. 
ejercerla se debe hacer con responsabilidad (Smith, 1999: 190-208). ${ }^{9}$

Chomsky se opone a los intelectuales que aceptan ser auxiliares del poder, porque buscan el poder para sí mismos y tienen fe en el valor de las instituciones occidentales a las que han sido sometidos como miembros de la clase dirigente, como lo establece Robert F. Barsky en Noam Chomsky une voix discordante. Bourdieu es complejo en su lenguaje y Chomsky se opone al lenguaje complicado, porque afirma que hay una voluntad deliberada por parte de los intelectuales y representantes políticos de ocultar los hechos utilizando un lenguaje confuso para mantener a las masas en la ignorancia. A principios de los ochenta, el posmodernismo francés tuvo un gran éxito en las ciencias humanas y sociales estadounidenses, pero Chomsky lo veía con desprecio debido a su concepción del rol de los intelectuales. Consideraba que el posmodernismo estaba destinado a servir sus propios intereses, complaciente y con un lenguaje autodestructor (1998: 211-252).

Algunos intelectuales franceses criticaban a Chomsky porque en sus trabajos utilizaba métodos viejos que no podían mostrar las sutilezas de los movimientos políticos. Su respuesta en 1995, fue que no querían ver lo que está claramente expuesto y deberían aprender "a decir la verdad, observar los hechos y buscar los criterios de una mínima racionalidad”. Además, les reprocha su rechazo a colaborar con el exterior. Barsky explica que el estadounidense tiene algunos prejuicios sobre el intelectual francés, por lo que no participó en los debates intelectuales políticos en Francia en los años sesenta y setenta (Barsky, 1998: 253 y 254).

9. Smith afirma que existen similitudes entre La trahison des clercs de Julien Benda y el primer artículo político de Chomsky:"La responsabilidad de los intelectuales", ya que Benda denunciaba como traidores morales a quienes traicionan la verdad y la justicia por consideraciones políticas o raciales, mientras que Chomsky aborda la responsabilidad de decir la verdad. Véase Smith, 1999: 190-208.

\section{2}


Por lo tanto, Chomsky desde finales de los años sesenta ha reprochado la política exterior de Estados Unidos y su imperialismo; asimismo, asocia la mundialización con la consolidación de empresas estadounidenses a nivel mundial. Sus investigaciones y excelente documentación lo han conducido a convertirse en uno de los críticos más importantes de las políticas de Estados Unidos.

\section{El compromiso de Chomsky en 2020}

Noam Chomsky es una de las figuras más críticas de las políticas de Estados Unidos y opinó en una entrevista que su país se dirige a un abismo sin un plan del Gobierno del presidente Donald Trump para enfrentar la pandemia del Covid-19, porque retiró financiamiento a la salud pública e ignora el gran avance del calentamiento global. Trump es un sociópata megalómano que solamente está interesado en su propio poder y no le importa lo que pasa en su país ni en el mundo. Hasta el momento (mayo de 2020) se han registrado 90,000 muertes en Estados Unidos por el coronavirus y habrá más porque no existe un plan coordinado. En cuanto Trump llegó al gobierno desmanteló la maquinaria de prevención de pandemias, retiró el financiamiento a los Centros para el Control de Enfermedades, y canceló los programas que trabajaban con científicos chinos para identificar virus, por lo que Estados Unidos no estaba preparado para una pandemia (La Jornada, 2020).

Asimismo, en mayo de 2020 Chomsky opinó que el presidente Trump es culpable de la muerte de miles de estadounidenses por utilizar la pandemia del Covid-19 para proyectarse en las elecciones presidenciales de noviembre. Trump cortó el financiamiento de salud e investigación y no ha asumido la responsabilidad en el combate del coronavirus, por lo que es culpable de las muertes en el país. Además, no financiar a la Organización Mundial de la Salud (oms) 
va a conducir a más muertes en Estados Unidos y Trump solamente ha estado buscando a quién culpar. Trump ha abandonado sus deberes al forzar a los gobernadores a asumir responsabilidad en el combate del Covid-19. Por otra parte, Chomsky fue entrevistado para el lanzamiento de "Internacional Progresista", una iniciativa global para unir, organizar y movilizar progresivamente fuerzas alrededor del mundo (Partington, 2020).

Posteriormente, Chomsky, tras las manifestaciones en todo Estados Unidos por el asesinato del afro-estadounidense George Floyd (25 de mayo de 2020) por parte de la policía de Minneapolis, opinó que la reacción popular ha sido sorprendente en el ámbito nacional con un "compromiso ferviente y solidaridad interracial" ("fervent commitment and interracial solidarity"). Esta situación ha expuesto toda la maldad que infecta a la Casa Blanca. Las marchas por la muerte de George Floyd son una táctica y tienen un impacto: enfocarse en la injusticia extrema que está envenenando la sociedad bajo el régimen neoliberal. Sin embargo, a partir de ahí, otras formas de activismo tienen que hacerse cargo. Chomsky observa la necesidad de una mejor dirección estratégica y se pregunta si emergerán movimientos populares que busquen terminar con el legado brutal de 400 años de racismo en su país (Pilkington, 2020).

Por lo tanto, puede observarse el compromiso de Chomsky, en busca de justicia y verdad, que lo lleva a criticar y denunciar al presidente de Estados Unidos, Donald Trump, por la crisis económica y la muerte de miles de estadounidenses por la pandemia del Covid-19. Asimismo, apoya las manifestaciones por la muerte de George Floyd porque se enfocan en la injusticia extrema y contra el racismo. 


\section{El compromiso de los intelectuales, de Sartre a Chomsky}

Durante "la Ocupación” y "la Resistencia” comenzó la participación y el compromiso de los intelectuales en Francia y durante la Guerra Fría se dio el esplendor de los intelectuales en Francia. Por lo tanto, esa época es considerada por algunos investigadores como la etapa dorada de la participación intelectual y el compromiso, con Sartre como el intelectual total y comprometido en todos los frentes, con su revista Les Temps Moderns respaldándolo en sus luchas y con disputas con otros intelectuales como Camus, Aron y Merleau-Ponty (Winock, 1999). Un personaje que sobresalió en la historia intelectual del siglo xx fue Sartre, porque fue la figura central intelectual de la Guerra Fría y hasta los años sesenta. A finales del siglo xx, en Francia se registró un silencio de los intelectuales por lo que surgieron los conceptos de intelectual colectivo de Bourdieu e intelectual transcriptor de Touraine, que buscaron contraponerse a la figura del intelectual total y comprometido de Sartre (Monnin, 2008).

Esta etapa dorada de la participación intelectual fue muy importante para América Latina porque durante los años sesenta la mayoría de los intelectuales latinoamericanos apoyaron la Revolución en Cuba y participaron en la revista cubana La casa de las Américas. Igualmente, desde los años treinta se realizaron discusiones similares sobre el compromiso de los intelectuales, como se observa en los casos de Octavio Paz (disputa con Neruda, ruptura con la izquierda y tránsito al liberalismo), Gabriel García Márquez (viajes por los países comunistas, Caso Padilla y Periodismo militante) y Mario Vargas Llosa (compromiso con la Revolución cubana, ruptura con la izquierda y tránsito al liberalismo). En Latinoamérica, en la segunda mitad del siglo xx existieron discusiones sobre el compromiso de los intelectuales y durante los años sesenta se retomó la figura 
de intelectual comprometido representada por Sartre, por lo que el compromiso fue uno de los temas más relevantes durante la década en el continente, asociado al triunfo de la Revolución cubana (Gilman, 2003).

En el caso de Estados Unidos, históricamente se ha encontrado alejado de la figura del intelectual que cristalizó con el caso Dreyfus. En la primera mitad del siglo xx los escritores estadounidenses estaban agrupados alrededor del PEN, que era una asociación no política y con el inicio de los Think tanks que se trata de un militantismo científico. A partir de los años setenta, las discusiones lingüísticas se consideraron "intelectuales" dentro de la academia estadounidense debido al "giro lingüístico", lo que pudo observarse en el caso Sokal, cuando se generó una discusión "intelectual" sobre el uso de ciertos lenguajes dentro de la academia. Posteriormente, a finales de siglo xx se habló sobre el militantismo científico de los Think tanks y el intelectual experto anglosajón (Hourmant y Leclerc, 2012: 9-14).

Noam Chomsky se considera un caso aparte dentro de los investigadores estadounidenses porque, como se ha mostrado en este artículo, no coincide con las posturas políticas de Estados Unidos y se asemeja a la figura del intelectual surgida en Francia con el caso Dreyfus, con un compromiso con la justicia, verdad y razón, lo que lo ha llevado a convertirse en el crítico estadounidense de la política de su país.

En los años ochenta, en Francia empezó la etapa del silencio de los intelectuales, mientras que en Estados Unidos Chomsky se estableció como un crítico de la sociedad y las políticas de su país. En esa época las discusiones se orientaban hacia la pérdida de las ideologías debido a la caída del socialismo con el Muro de Berlín, el fin del socialismo-comunismo, altermundismo, liberalismo, neoliberalismo, el intelectual académico ("experto") y los estudios sobre historia intelectual. Es decir, el radicalismo político o contestación ideológica de Chomsky remite al compromiso 
de los intelectuales en Francia o en América Latina, en una época cuando las discusiones académicas estaban orientadas hacia otros temas.

\section{Sartre y Chomsky en las ideas políticas en América Latina}

Una forma en que se puede comprobar el impacto de las ideas políticas de Sartre y de Chomsky en la actualidad en América Latina, es que si se utiliza Google Scholar (como cualquier investigador en el año 2020) para rastrear cómo han sido interpretadas sus ideas, existe una gran cantidad de ensayos y artículos. Por consiguiente, se debe ser más preciso, si uno busca en Google Scholar "Sartre ideas políticas América Latina", limita la búsqueda al idioma español y de 2015 a 2020 (el 15 de mayo de 2020 es cuando se comenzó este artículo) se encuentran 4,510 citas, es decir, existen 4,510 trabajos académicos sobre el tema. Por otra parte, si uno busca "Sartre ideas políticas México" existen 6,930 citas.

Por otro lado, si se utiliza Google Scholar y se escribe "Chomsky ideas políticas América Latina", limita la búsqueda al idioma español y de 2015 a 2020 (hasta el 15 de mayo de 2020), se encuentran 3,990 citas, es decir, existen 3,990 trabajos académicos sobre el tema. Asimismo, si uno busca "Chomsky ideas políticas México" aparecen 6,380 citas.

Por consiguiente, la cantidad de trabajos académicos aumenta alrededor del 50\% cuando se investiga en Google Scholar sobre México y las ideas políticas de Sartre y Chomsky. Es claro que una buena cantidad de esos trabajos académicos e investigaciones pudieron haber sido escritos en España y (por cuestiones del idioma) el resto de los trabajos pertenecen a Latinoamérica. Asimismo, cuando se observa el origen de estas investigaciones puede notarse que un gran porcentaje fueron desarrolladas en las univer- 
sidades de todos los países latinoamericanos. Por lo tanto, resulta importante conocer la obra de Sartre y Chomsky para entender su influencia, en 2020, en las ideas políticas de América Latina.

\section{Guerra Fría, compromiso y dictaduras en América Latina en el siglo $x x$}

Una etapa importante para los intelectuales latinoamericanos ocurrió después de la Segunda Guerra Mundial y durante la Guerra Fría, cuando se acentuaron las posturas de izquierda y derecha y se polarizó el apoyo a Estados Unidos o a la URss. Decadencia y caída de la ciudad letrada, de Jean Franco, aborda los temas vinculados al contexto posterior a la Segunda Guerra, los aspectos culturales y los artistas comunistas latinoamericanos que se vieron implicados. Franco realiza un recuento de temas vinculados al comunismo en América Latina, por lo que se infiere que la caída está asociada a la trasposición de la Guerra Fría en Latinoamérica (2003).

Germán Alburquerque en La trinchera letrada propone que existen cinco etapas de la Guerra Fría desde 1945 hasta 1990: 1) 1945-1959. La Guerra Fría como conflicto bipolar mundial. 2) 1959-1966. "Latinoamericanización" de la Guerra Fría que inicia con la Revolución cubana con la adhesión de los intelectuales latinoamericanos, lo que acentúa su antinorteamericanismo. 3) 1966-1975. "Tercermundialización" de la Guerra Fría, con el efecto de la Conferencia Tricontinental de La Habana en 1966 y la Guerra de Vietnam, por lo que los intelectuales declararían su tercermundismo militante. 4) 1975-1985. "Centroamericanización” de la Guerra Fría debido al triunfo sandinista en 1979 y apoyo intelectual, que genera un nuevo enfrentamiento con Estados Unidos. 5) 1985-1990. El repliegue, con el fin de las dictaduras en Sudamérica, la Perestroika y la

\section{8}


posterior caída de la Unión Soviética (Alburquerque, 2011: 289 y 290). El concepto de "trinchera letrada" se refiere a la participación de los intelectuales latinoamericanos durante esta guerra en dos bloques: crítica a Estados Unidos o crítica a la Unión Soviética.

Los años sesenta son considerados como la etapa más notoria del compromiso en América Latina, marcada por la Revolución cubana que durante esa década tuvo el apoyo de una gran cantidad de intelectuales latinoamericanos, como se confirma en Entre la pluma y el fusil de Claudia Gilman. Los debates del escritor revolucionario en América Latina son revisados en esta obra, lo que permite entender la importancia del compromiso en el continente durante los años sesenta y setenta. Además, se presenta una explicación de cómo se formó la comunidad intelectual alrededor de la Revolución cubana hasta su ruptura como consecuencia del Caso Padilla en 1971 (2003).

Por otra parte, en América Latina en el siglo xx existieron dictaduras en algunos países porque representaban una forma de poder autoritario y tiránico, donde el único límite era la voluntad de quienes lo ejercían. En esos países no existía la democracia, es decir, un régimen representativo dotado de legitimidad política (Hermet, Badie, Birnbaum y Braud, 2015: 78 y 79). Durante los años sesenta y setenta en América Latina se vivió un proceso de militarización que utilizó como acto político la forma del golpe de Estado (Serrano, 2010: 176). En los años setenta se instalaron regímenes militares en Argentina, Chile y Uruguay y se continuó con el experimento brasileño (Camacho, Lechner, Brunner, Flisfisch, Garreton, Moulian, Varas y Portales, 1982: 162). Estos periodos dictatoriales en la segunda mitad del siglo xx constituyeron una forma aberrante y anormal del ejercicio del poder político (Bohoslavsky, Franco, Iglesias y Lvovich, 2010: 17). A diferencia de la mayor parte de los países latinoamericanos, México no tuvo una dictadura 
militar, pero el PRI, que gobernó por más de 70 años, es un ejemplo de la tradición corporativo-autoritaria en un gobierno civil (Klaiber, 1997: 437).

La democracia ha llegado a América Latina luchando contra el subdesarrollo económico y la violencia del Estado; a partir de los años ochenta la democracia se volvió más segura, lo que condujo a la liberalización económica (Smith, 2009: 269-280). Sin embargo, a pesar de este proceso la democracia latinoamericana se ha definido por ser limitada, defectiva e incompleta (Magallón, 2003). De esta forma, los dos fenómenos políticos más importantes en el continente en la segunda parte del siglo xx fueron el colapso y la restauración de la democracia (Klaiber, 1997: 437).

Por consiguiente, el hecho de que en la segunda parte del siglo xx en América Latina hayan existido dictaduras permite explicar la influencia, en el continente, de las ideas sobre el intelectual comprometido que se popularizaron con Sartre. Asimismo, se comprueba una parte de las ideas de François Dosse, presentadas al inicio de este artículo, porque señala que el modelo del caso Dreyfus del intelectual comprometido ha tenido en América Latina un buen terreno de transferencias culturales debido a los procesos de independencia nacional y protestas contra el establecimiento de dictaduras militares.

\section{Conclusiones}

Jean-Paul Sartre representa al intelectual comprometido, crítico y denunciador, por lo que remite a la figura del intelectual que cristalizó en Francia con el caso Dreyfus. Sartre sobresale en la historia intelectual del siglo xx y sus ideas fueron clave en la Francia de la posguerra y hasta finales de los años sesenta. Sartre argumentaba que el escritor debía aceptar su época y no perderse nada de ella, porque era imposible evadirla, incluso si decidía callarse. 
De tal forma, el escritor debía tomar conciencia de que todo escrito poseía un sentido y abrazar su época. Así, Sartre después de la guerra era visto como el "intelectual total", comprometido en todos los frentes de la actualidad política.

En el caso de Chomsky, a pesar de que ha criticado la figura intelectual que se popularizó en Francia en el siglo $\mathrm{xx}$, no ha podido evadir el compromiso porque sabe que cada palabra tiene consecuencias; cada silencio también. Chomsky ha aceptado su época, lo que lo ha llevado a ser el crítico del imperialismo de Estados Unidos, denunciar al presidente de Estados Unidos por la crisis económica y la muerte de miles de estadounidenses por la pandemia del Covid-19, así como apoyar las manifestaciones contra el racismo por la muerte de George Floyd.

Como ha podido observarse, la historia intelectual trabaja de forma conjunta los autores, sus obras y el contexto social en una aproximación externa que privilegia las redes de sociabilidad, remitiendo a la historia política y la historia de las ideas políticas. Por lo tanto, mi aportación a la historia intelectual es que por medio de este artículo se ha presentado la evolución del compromiso intelectual desde el caso Dreyfus, pasando por las ideas de Sartre hasta llegar al compromiso intelectual que manifiesta Chomsky en 2020, es decir, un investigador activista. Asimismo, se mostró el contexto de América Latina en la segunda mitad del siglo xx (la Guerra Fría, la Revolución cubana y el periodo de dictaduras) que ayuda a entender tanto la participación de los intelectuales latinoamericanos en búsqueda de verdad, justicia y democracia, como la influencia de las ideas intelectuales de Sartre y Chomsky.

Esto no significa que Chomsky continúe con las ideas de Sartre, ni que busque ser el intelectual comprometido en todos los frentes políticos. No obstante, a pesar del distanciamiento de Chomsky de la figura del intelectual surgida en Francia, pueden encontrarse en sus ideas políticas la 
búsqueda de verdad, justicia y razón. Esta situación lo ha llevado a ser uno de los críticos de las políticas de Estados Unidos, por lo que sus ideas en obras y artículos se han convertido en una referencia en América Latina.

Las ideas políticas de Sartre han tenido un gran impacto a nivel mundial y el hecho de que él y Simone de Beauvoir viajaron a Brasil y a Cuba en los años sesenta y se entrevistaron con Fidel Castro y el Che Guevara (símbolos de la izquierda latinoamericana), contribuyó a que las teorías sartreanas tengan tanto impacto en Latinoamérica. Además, Sartre apoyó a los estudiantes en sus luchas y se manifestó contra Estados Unidos por la Guerra de Vietnam, lo que coincide con los ideales de algunos de los movimientos en América Latina, por lo que resulta consecuente que las ideas políticas de Sartre sean tan citadas en esta parte del continente.

Noam Chomsky presenta matices que remiten a la figura del intelectual por su compromiso con la justicia y la verdad. Es un académico que no coincide con las políticas de Estados Unidos (su país natal) y ha explicado su participación contra los movimientos populares en América Latina. Su búsqueda de justicia lo ha llevado a convertirse en un crítico de la política de Estados Unidos y su imperialismo. Chomsky representa al investigador activista, en un país donde no existe una tradición del compromiso intelectual.

Una etapa importante para los intelectuales latinoamericanos ocurrió después de la Segunda Guerra Mundial cuando se extremaron las posturas de izquierda y derecha. Estas ideas continuaron en los años sesenta, que son considerados como la etapa más importante del compromiso en Latinoamérica, por el impacto que tuvo la Revolución cubana hasta el caso Padilla en 1971. Durante esa etapa en América Latina existieron dictaduras y se vivió un proceso de militarización, por lo que las ideas sobre el compromiso tuvieron un gran impacto en los intelectuales latinoameri- 
canos, quienes se manifestaron en contra de las dictaduras y a favor de la democracia.

Por tales motivos, las ideas políticas de Sartre y Chomsky son muy citadas en América Latina porque representan al intelectual crítico y denunciador, con un compromiso con la verdad, justicia y razón. En Latinoamérica los pensadores de derecha son muy criticados e incluso son considerados los intelectuales orgánicos del Estado. Así, el pensamiento crítico de los pensadores, investigadores y estudiantes de las universidades de América Latina ha encontrado, en las ideas políticas de Sartre y Chomsky, una herramienta que le ha permitido analizar y criticar la sociedad contemporánea, así como manifestarse en contra de las injusticias y dictaduras.

Alburquerque, G. (20II). La trinchera letrada. Intelectuales latinoamericanos y Guerra Fría. Santiago:Ariada Ediciones.

Barsky, R. (1998). Noam Chomsky une voix discordante. París: Éditions Odile Jacob.

Bejerano, P.G. (20I4, 20 de octubre). Por qué Sartre dijo no al Nobel. Eldiario.es. Recuperado el I de junio de 2020, de https://www.eldiario.es/cultura/sartre-rechazo-nobel_0_3 I3568954.html

Bohoslavsky, E., Franco, M., Iglesias, M.,y Lvovich, D. (Comps.). (2010). Problemas de historia reciente del Cono Sur. Volumen I. Buenos Aires: Universidad Nacional de General Sarmiento.

Bonfiglioli, C., y Budgen, S. (Coords.). (2006). La planète altermondialiste. Guide critique de la pensée de:SamirAmin, Pierre Bourdieu, Bernard Cassen, Noam Chomsky, Susan George, Naomi Klein, Sous-Cdt Marcos, Toni Negri,Arundhati Roy, etc. París: Lés éditions Textuel.

Cabestan, P. (2009). Dictionnaire Sartre. París: Ellipses Édition. 
Bibliografía

Camacho, D., Lechner, N., Brunner, J., Flisfisch, A, Garreton, M., Moulian, T., Varas, A., y Portales, C. (1 982). Autoritarismo y alternativa populares en América Latina. Costa Rica: Ediciones FLACSO.

Chomsky, N. (1999). (En conversación con Heinz Dieterich). América Latina. De la colonización a la globalización. Madrid: Ediciones Cátedra.

—. (2004). Idéologie et pouvoir. Bélgica: Éditions EPO.

.(2010). Raison \& liberté. Sur la nature humaine, l'éducation \& le rôle des intellectuels. Marseille:Agone.

Delacroix, C., Dosse, F., Garcia, P., y Offenstadt, N. (Dir.). (2010). Historiographies, concepts et débats. París: Gallimard.

Denis, B. (2000). Littérature et Engagement, de Pascal à Sartre. París: Éditions du Seuil.

Dosse, F. (2003). La marche des idées. Histoire des intellectuels, histoire intellectuelle. París: Éditions La Découverte.

Franco, J. (2003). Decadencia y caída de la ciudad letrada. La literatura latinoamericana durante la Guerra Fría. Barcelona: Debate.

Galster, I. (Dir.) (200I). La naissance du phénomène Sartre. Raisons d'un succès 1938-1945. París: Éditions du Seuil.

Gilman, C. (2003). Entre la pluma y el fusil:Debates y dilemas del escritor revolucionario en América Latina. Buenos Aires: Siglo XXI Editores Argentina.

Hermet, G., Badie, B., Birnbaum, P., y Braud, P. (20I5). Dictionnaire de la science politique et des institutions politiques. París:Armand Colin.

Hofmeister, W., y Mansilla, H. C. F. (2003). Intelectuales y política en América Latina:El desencantamiento del espíritu crítico. Rosario: Homo Sapiens.

Hourmant, F., y Leclerc, A. (Dir.). (20I2). Les intellectuels et le pouvoir: Déclinaisons et mutations. Rennes: Presses universitaires de Rennes.

\section{4}


Klaiber, J. (1997). Iglesia, dictaduras y democracia en América Latina. Lima:Fondo Editorial de la Pontificia Universidad Católica del Perú.

La Jornada. (2020, 25 de mayo). eU va al abismo sin un plan contra el Covid-19: Chomsky. La Jornada. Recuperado el I de junio de 2020, de https://www.jornada.com.mx/ ultimas/mundo/2020/05/25/eu-va-al-abismo-sin-un-plancontra-el-covid-19-chomsky-34I I.html

Leymarie, M. (Dir.). (2003). L'histoire des intellectuels aujourd'hui. París: Presses Universitaires de France.

Magallón, M. (2003). La democracia en América Latina. México: UNAM-CCYDEL/Plaza y Valdés.

Monnin, N. (2008). Sartre. París: Les belles lettres.

Münster,A., y Wallet, J.W. (Dir.). (2006). Sartre: le philosophe, le intellectuel et la politique. Les actes du colloque d'Amiens (Mai 2005). París: L'Harmattan.

Partington, R. (2020, I I de mayo). Trump is culpable in deaths of Americans, says Noam Chomsky. The Guardian. Recuperado el I de junio de 2020, de https://www. theguardian.com/us-news/2020/may/I I/donald-trumpis-culpable-in-deaths-of-americans-says-noam-chomsky Pilkington, E. (2020, 10 de junio). After 15 stunning days of anti-racist protests... what happens next? The Guardian. Recuperado el 14 de junio de 2020, de https://www. theguardian.com/us-news/2020/jun/ I 0/george-floydprotests-what-happens-next

Sartre,J. P. ( 1 957). ¿Qué es la literatura? Buenos Aires: Losada. Serrano, F.V. (20I0). Estado, golpes de Estado y militarización en América Latina: Una reflexión histórico-política. Revista Argumentos, Nueva época, año 23, núm. 64. México: UAM-Xochimilco.

Smith, N. ( 1999). Chomsky. Ideas and ideals. Cambridge: Cambridge University Press. 
Bibliografía $\quad$ Smith, P. H. (2009). La democracia en América Latina. Madrid/ Barcelona/Buenos Aires: Universidad de Alcalá-Instituto de Estudios Latinoamericanos.

Touraine, A. (1999). Comment sortir du libéralisme? París: Fayard.

Winock, M. (1999). Le siècle des intellectuels. París: Éditions du Seuil.

Zarka, Y. C. (20I0). La destitution des intellectuels et autres réflexions intempestives. París: Presses Universitaires de France. 